\title{
Physical Functioning in Patients with Chronic Obstructive Pulmonary Disease Treated with Tiotropium/Olodaterol Respimat in Routine Clinical Practice in Italy
}

\author{
Mauro Carone - Alfio Pennisi - Mariella D'Amato - Alfeo Fiore Donati • \\ Alberto Ricci · Carla Scognamillo · Li Chun • Maria Aliani • \\ Valeria Ronsivalle · Girolamo Pelaia
}

Received: April 15, 2020 / Published online: June 18, 2020

(C) The Author(s) 2020

\section{ABSTRACT}

Introduction: Clinical studies have shown significant improvements in exercise capacity in patients with chronic obstructive pulmonary disease (COPD) who are treated with a tiotropium/ olodaterol fixed-dose combination (FDC). However, the effects of this treatment, which is administered in a single device, on physical functioning in a real-life setting of patients with COPD had not been fully determined.

Digital Features To view digital features for this article go to https://doi.org/10.6084/m9.figshare.12409025.

Electronic supplementary material The online version of this article (https://doi.org/10.1007/s41030020-00122-9) contains supplementary material, which is available to authorized users.

M. Carone $(\bowtie) \cdot$ M. Aliani

Division of Pneumology, Istituti Clinici Scientifici

Maugeri IRCCS, Via Salvatore Maugeri, 4, 27100

Pavia, Italy

e-mail: mauro.carone@icsmaugeri.it

A. Pennisi · V. Ronsivalle

Department of Pneumology, Casa Di Cura Mons.

Calaciuria, Catania, Italy

M. D'Amato

UOSD Pneumology, Ospedale Monaldi-AO Dei

Colli, Napoli, Italy

A. F. Donati

UOC Pneumology, Ospedale S. Salvatore, L'Aquila, Italy
Methods: An open-label, observational study was conducted in 309 patients with COPD from 29 sites across Italy who received tiotropium/ olodaterol FDC for 6 weeks. Physical functioning was evaluated using the Physical Functioning Questionnaire (PF-10). The primary endpoint was the proportion of patients with therapeutic success, defined as a ten-point increase in the PF-10 score from the baseline visit. Secondary endpoints were absolute changes in PF-10 score from baseline visit, the patient's general condition assessed by the Physician's Global Evaluation (PGE) score, and patient satisfaction with treatment, inhaling and handling of the device.

Results: According to the Global Initiative for Chronic Obstructive Lung Disease (GOLD) multimodality assessment, most patients were

\author{
A. Ricci \\ Department of Pneumology, Azienda Ospedaliera \\ Sant'Andrea, Roma, Italy \\ C. Scognamillo \\ Boehringer-Ingelheim S.P.A, Milan, Italy \\ L. Chun \\ Boehringer-Ingelheim, Ridgefield, CT, USA \\ G. Pelaia \\ Department of Scienze Mediche E Chirurgiche, \\ Università "Magna Grecia", Catanzaro, Italy
}


allocated to groups B (44.4\%) and D (24.5\%). Comorbidities were present in $73.9 \%$ of the patients. The primary endpoint was reached in more than half of the patients $(52.5 \%)$, especially in groups B and D of GOLD. Patients' satisfaction with treatment, inhaling and handling of device was high, with a range of more than $86 \%$ to more than $89 \%$, and very high in both groups $\mathrm{B}$ and $\mathrm{D}$. The rates of drug-related adverse events were very low.

Conclusions: This real-life study showed that the tiotropium/olodaterol FDC treatment delivered via the Respimat device improves physical functioning and general patients' condition and is associated with a high degree of satisfaction and very low rates of drug-related adverse events, regardless of the group they belong to and their comorbidities.

Clinical Trial ID: NCT03003494.

Keywords: COPD; Exercise capacity; Fixeddose combination; Health status; Inhaling device; Long-acting dual bronchodilation; Patient-reported outcomes; Olodaterol; Physical functioning; Tiotropium

\section{Key Summary Points}

Why carry out this study?

Tiotropium/olodaterol fixed-dose combination (FDC) improves exercise capacity in patients with chronic obstructive pulmonary disease (COPD).

The effects of FDC, administered in a single device, on physical functioning in a real-life setting had not been fully determined.

\section{What was learned from the study?}

Self-reported physical functioning and the general condition of COPD patients treated with tiotropium/olodaterol FDC via the Respimat device improved.

Both improvement and satisfaction were observed across all GOLD ABCD classification groups.

\section{INTRODUCTION}

Inactivity has a crucial role in the development of extra-pulmonary effects of chronic obstructive pulmonary disease (COPD), including skeletal muscle weakness, osteoporosis, and cardiovascular disease, and leads to an accelerated decline of lung function $[1,2]$ and an increased risk of hospitalization [3]. Moreover, a lower level of physical activity has the strongest predictive factor of death in patients with COPD [4] and are associated with poorer pulmonary outcomes and quality of life [5]. For this reason, the global initiative for chronic obstructive lung disease (GOLD) recommends that all patients with COPD participate in daily physical activity [6]. Despite this, the reduction of physical activity is very common in COPD, even starting from the GOLD stage I [7]. Several interventions can be established to increase physical activity and adequate bronchodilator inhalation therapy is one of the most important among them [8-10].

The GOLD document recommends administering a long-acting muscarinic antagonist (LAMA) with a long-acting beta-agonist (LABA) in patients not adequately controlled on a single long-acting bronchodilator treatment [6]. This has prompted the development of the LAMA + LABA fixed-dose combination (FDC) [11], which has been demonstrated to be safe and effective, and also fits the patients' needs.

Tiotropium/olodaterol is an inhaled FDC of the long-acting muscarinic antagonist tiotropium bromide and the long-acting $\beta_{2}$ adrenergic agonist olodaterol, which was shown to improve pulmonary function, rate of exacerbation, patient-reported outcomes (such as dyspnea, use of rescue medication and health status), exercise capacity (e.g., endurance time) compared with placebo and its mono-components in several clinical trials and meta-analyses [12-24].

However, 'field-practice' studies have major importance for a comprehensive evaluation of treatments for COPD $[25,26]$. The effectiveness of tiotropium/olodaterol in a field-practice scenario has been assessed in some observational studies, which have been conducted in Central 
Europe and Japan [27-30]. However, further evidence from other countries is necessary, since treatment outcomes vary in different cultural and geographical areas [31]. Moreover, a detailed report of data on physical functioning and other relevant measures, such as health status and treatment satisfaction, may be relevant in the evaluation of any treatment for COPD [25].

We conducted an observational, prospective, multicenter study in Italy, which aimed to evaluate physical functioning, health status, and treatment satisfaction in patients with COPD who were treated with tiotropium/olodaterol FDC inhalation solution, during a 6-week routine clinical practice.

\section{METHODS}

\section{Study Design}

This open-label, prospective observational study was conducted in 29 pulmonary centers across Italy from July 2017 to May 2018. The study protocol was approved by the local institutional Ethics Committee (Comitato Etico Regione Calabria Sezione Area Centro) and written informed consent was obtained from each participant. This study is registered with ClinicalTrials.gov (NCT03003494) and was conducted in line with the Declaration of Helsinki.

\section{Patients}

Consecutive patients with COPD aged $\geq 40$ years who required long-acting dual bronchodilation (LAMA + LABA) treatment with tiotropium/olodaterol were enrolled. Patients were excluded if they had known contraindications to tiotropium/olodaterol according to the Spiolto ${ }^{\circledR}$ Respimat $^{\circledR}$ SmPC [32]. Patients who were in treatment with LABA plus inhaled corticosteroids were also excluded to avoid double LABA treatment. Patients who have been treated with a LABA/LAMA combination (free and fixed dose) in the previous 6 months were also excluded. Disease severity according to GOLD multimodality assessment [6] was not considered as an eligibility criteria, but treatment was assigned according to clinical evaluation, as widely reported in the real-life setting, where patients follow a different therapy with respect to GOLD recommendations $[33,34]$.

\section{Treatment}

Patients were started on tiotropium/olodaterol FDC $(5 \mu \mathrm{g}$ tiotropium $+5 \mu \mathrm{g}$ olodaterol $)$ as an inhalation solution through the Respimat device for 6 weeks, which corresponded to the average time between two medical consultations. All patients were properly trained in using the Respimat device.

\section{Variables}

The following variables were collected and assessed at baseline (visit 1) and/or after the 6-week treatment (visit 2):

Visit 1:

- Demographic data

- Medical history on COPD (initial diagnosis), exacerbations in the last 12 months, as well as spirometry (performed either before or after initiation of treatment) and GOLD severity of obstruction at the time of visit [6]

- Smoking history and pack-years

- Concomitant diseases and medication

- Respiratory therapy: initiation of Spiolto ${ }^{\circledR}$ Respimat $^{\circledR}$, treatment with other respiratory therapeutics (within 6 months prior to study treatment)

- Severity of dyspnea based on the modified Medical Research Council dyspnea scale [35]

- Physical Functioning Questionnaire (PF-10)

- General condition (assessed by Physician's Global Evaluation [PGE] score)

Visit 2:

- Changes in smoking history since visit 1

- Changes in concomitant diseases and medication since visit 1

- Respiratory therapy: regular use of Spiolto ${ }^{\circledR}$ Respimat $^{\circledR}$ therapy (patient-reported 
adherence) and willingness to continue therapy, changes in other respiratory therapies since visit 1

- PF-10

- General condition (assessed by PGE score)

- Patient satisfaction survey

- Safety: adverse drug reactions associated with Spiolto ${ }^{\circledR}$ Respimat $^{\circledR}$, as rated by the CTCAE, version 4.0.

The PF-10 questionnaire assesses ten subdomains about everyday physical activity and functioning of the validated 36-Item Short Form Health Survey (SF-36) [36]. PF-10 has previously been used in the COPD setting to measure physical functioning improvements in clinical practice [30]. Each PF-10 item may be answered with "yes, limited a lot", "yes, limited a little", or "no, not limited at all", with a score of 1,2 or 3 , respectively. The scores for the 10 items were summed and transformed into a range of 0-100, with higher scores representing better physical functioning, according to Sauer et al. [30]. It can be easily completed within few minutes.

PGE is an eight-point scale in which the treating physician evaluated the patient's general condition as poor (1-2), satisfactory (3-4), good (5-6) or excellent (7-8) [37].

Patients satisfaction was measured using a seven-point ordinal scale from very dissatisfied to very satisfied, referring to satisfaction with treatment, inhaling from the device and handling the device.

\section{Endpoints}

The primary endpoint of the study was the proportion of patients who achieve therapeutic success at visit 2 , defined as a ten-point increase in the PF-10 score between visit 1 and visit 2 . The threshold of ten-point change was based on the distribution-based method by Cohen [38]. Based on two 1-year studies conducted in patients with COPD, the baseline standard deviation for physical functioning scores was 22. The minimal important difference ranged between 4 and 11 [30]. Secondary endpoints were: (1) the evaluation of the absolute changes in PF-10 score from visit 1 to visit 2; (2) patient's general condition assessed by the PGE score at visit 1 and at visit 2; and (3) patient satisfaction with tiotropium/olodaterol at visit 2 .

\section{Data Analysis}

Data were analyzed by descriptive statistics. Due to the intents of the study, no formal sample size calculation was performed. Data were analyzed in the overall population and according to the GOLD severity assessment [6].

Any patient who received at least one dose of tiotropium/olodaterol was included in the safety population. Demographic/baseline data were analyzed in the safety population. Patients in the safety population who had a PF-10 score at visit 1 and visit 2 comprised the full analysis set (FAS). All analyses were performed using the SAS 9.4 software.

\section{RESULTS}

\section{Patients Characteristics}

In total, 309 patients were screened, and 306 received tiotropium/olodaterol (safety population); the FAS population consisted of 278 patients (Fig. 1).

Table 1 depicts the baseline characteristics of the TS population. Mean age was $71 \pm 9$ years; $21.6 \%$ of the patients were younger than 65 years. Most patients $(n=216 ; 70.6 \%)$ were male. Most of them had a degree of severity of obstruction of grade II $(n=137 ; 44.8 \%)$ or III $(n=84 ; 27.5 \%)$ and modified Medical Research Council scores of $2(n=93 ; 30.4 \%)$ or $3(n=80$; $26.1 \%)$. According to the ABCD multimodality assessment of the GOLD 2017 update, $44.4 \%$ of the patients were allocated to group $B$ and $24.5 \%$ to group D. One exacerbation was reported in $40.5 \%$ of the patients of the TS, and two or three exacerbations occurred in $17.7 \%$ and $6.9 \%$ of the patients, respectively.

Mean PF-10 score was of $48.3 \pm 26.0$ (95\% CI 45.2-51.4), and a PGE score was $3(n=69$; $24.8 \%)$ or $4(n=72 ; 25.9 \%)$ in most patients, corresponding to a satisfactory general 


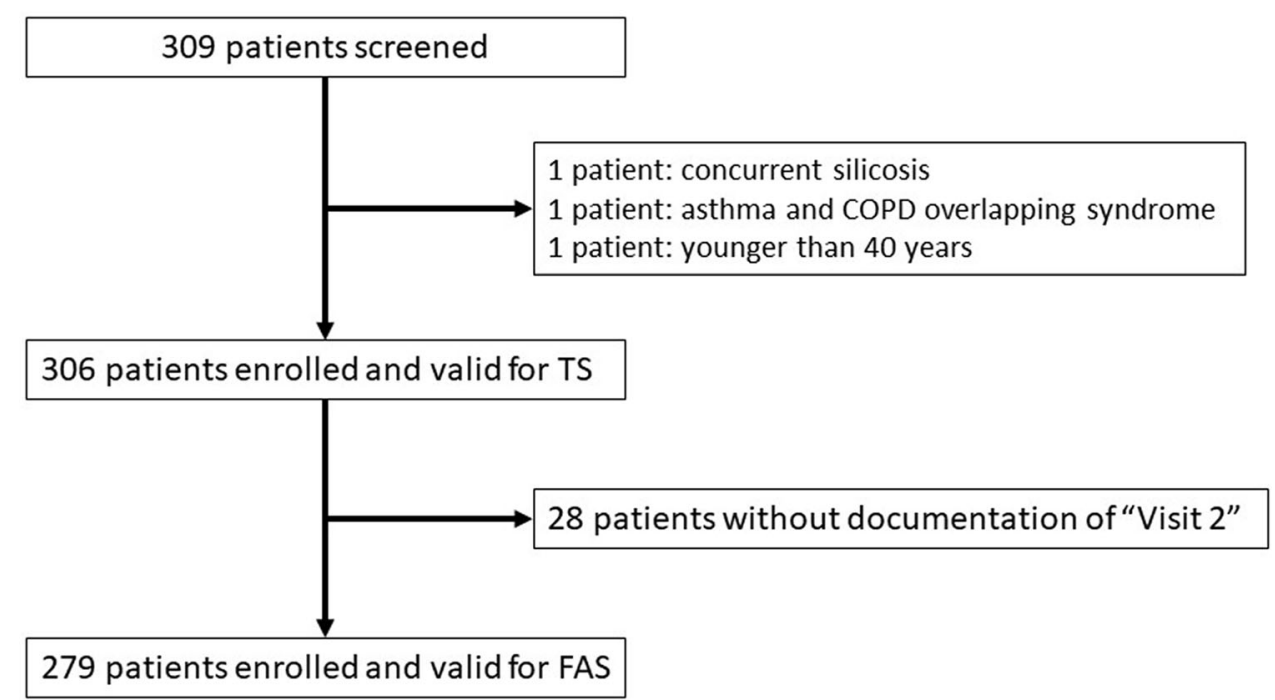

Fig. 1 Patient flow chart

condition (Table 1). A total of 190 patients (62.1\%) were already taking therapy for COPD (Table 2).

Concomitant diseases were present in $73.9 \%$ of the patients who were included in the safety population, and $64.4 \%$ of subjects were treated with concomitant medications (Table S1). In the majority of cases (195 patients, 63.7\%), the concomitant medications were continued during the study and in only four patients $(1.3 \%)$ new prescriptions were issued at enrollment.

\section{Therapeutic Success}

Achievement of therapeutic success was reported in more than half of the patients in the FAS (52.5\%; 95\% CI 46.5-58.5\%) (Table 3). When stratifying patients according to ABCD grouping, therapeutic success was achieved in $23.4 \%$ of patients in group A (95\% CI 12.3-38.0), $60.0 \%(51.0-68.5)$ of those in group B, $40.0 \%$ (23.9-57.9) of subjects in group C, and $65.1 \%$ (52.4-76.5) of patients in group D (Table 3).

\section{Change in PF-10 Score}

The absolute median change of PF-10 score between visit 1 and visit 2 was of ten points (range, 60 to 80 ) with a mean change of $11.2 \pm 21.2$ points (95\% CI 8.8-13.8) (Table S2).
Median changes from baseline were 5 (range, 60 to 60 ), 10 (range, 50 to 80 ), 0 (range, 45 to 45 ) and 10 (range, 25 to 75 ), in patients assigned to GOLD groups A, B, C, and D, respectively.

\section{PGE Scores}

Overall, PGE scores improved over the study period: at visit 2, PGE score was 6 in $40.7 \%$ of patients (Fig. 2). In a post hoc unplanned analysis, a positive relationship between PF-10 and PGE scores was found by Spearman's correlation analysis (Table S3).

\section{Patients' Satisfaction}

Most patients in the FAS $(n=240 ; 86.3 \%)$ were satisfied or rather satisfied with the tiotropium/ olodaterol FDC treatment, as well as with the Respimat device (Table 4). Similar results were shown when stratifying patients according to disease severity (Table S4). In a post hoc unplanned analysis, a $\chi^{2}$ test analysis indicated no significant correlation between age and patient satisfaction (treatment: $p=0.230$; inhaling from device: $p=0.500$; handling of device: $p=0.075$ ) and among the four GOLD severity groups (treatment: $p=0.212$; inhaling from device: $p=0.170$; handling of device: $p=0.505)$. 
Table 1 Demographics and clinical characteristics of the safety population at baseline (visit 1)

\begin{tabular}{|c|c|}
\hline Data & Patients, $n(\%)^{\mathrm{a}}$ \\
\hline Number of patients & 306 \\
\hline \multicolumn{2}{|c|}{ Age at enrollment (years) } \\
\hline Mean $\pm S D$ & $71 \pm 9$ \\
\hline Min-max & $40-91$ \\
\hline Median & 72 \\
\hline$<65$ years, $n(\%)$ & $66(21.6)$ \\
\hline$\geq 65$ years, $n(\%)$ & $240(78.4)$ \\
\hline \multicolumn{2}{|l|}{ Gender, $n(\%)$} \\
\hline Male & $216(70.6)$ \\
\hline \multicolumn{2}{|c|}{ Interval between initial diagnosis of COPD and enrolment (years) } \\
\hline Mean $\pm S D$ & $7.5 \pm 7.8$ \\
\hline Min-max & $0.0-48.0$ \\
\hline Median & 5.0 \\
\hline \multicolumn{2}{|c|}{ Severity of obstruction by spirometry } \\
\hline 1 & $41(13.4)$ \\
\hline 2 & $137(44.8)$ \\
\hline 3 & $84(27.5)$ \\
\hline 4 & $42(13.7)$ \\
\hline Not available & $2(0.7)$ \\
\hline \multicolumn{2}{|l|}{ mMRC Questionnaire } \\
\hline Grade 0 & $24(7.8)$ \\
\hline Grade 1 & $71(23.2)$ \\
\hline Grade 2 & $93(30.4)$ \\
\hline Grade 3 & $80(26.1)$ \\
\hline Grade 4 & $38(12.4)$ \\
\hline \multicolumn{2}{|c|}{ COPD degree of severity according to the GOLD 2017 ABCD classification } \\
\hline A & $55(18.0)$ \\
\hline B & $136(44.4)$ \\
\hline $\mathrm{C}$ & $40(13.1)$ \\
\hline $\mathrm{D}$ & $75(24.5)$ \\
\hline A/B pooled & $191(62.4)$ \\
\hline C/D pooled & $115(37.6)$ \\
\hline
\end{tabular}


Table 1 continued

\begin{tabular}{ll}
\hline Data & Patients, $\boldsymbol{n}(\%)^{\mathbf{a}}$ \\
\hline 0 & $94(30.7)$ \\
1 & $124(40.5)$ \\
2 & $54(17.7)$ \\
3 & $21(6.9)$ \\
$>3$ & $13(4.2)$ \\
Physical Functioning Questionnaire (PF-10) & \\
Mean \pm SD & $48.3 \pm 26.0$ \\
$95 \%$ CI & $45.23-51.36$ \\
Median (min-max) & $50(0-95)$ \\
Physician's Global Evaluation (PGE) & \\
1 & $2(0.7)$ \\
2 & $5(1.8)$ \\
3 & $69(24.8)$ \\
4 & $72(25.9)$ \\
5 & $65(23.4)$ \\
6 & $46(16.6)$ \\
7 & $19(6.8)$ \\
8 & $0(0)$ \\
\hline
\end{tabular}

a Unless otherwise stated

Safety

In total, three investigator-defined drug-related AEs (grade 1 tremor, grade 1 urticaria and grade 3 hypertension) occurred in three patients (1\%). All of these events have recovered and two of the events required treatment. One patient had a fatal AE (death) without a suspected causal relationship to the study treatment (Table S5).

\section{DISCUSSION}

Physical activity is recognized as a relevant measure of outcome in clinical studies of COPD, during programs of rehabilitation, and as patients' self-management [39]. Indeed, regular physical activity is also strongly recommended by several guidelines of scientific societies for the maintenance of pharmacotherapy, in addition to other physical and social aspects of a healthier lifestyle for patients with this disease [6, 27].

In this prospective study, we described physical functioning as a surrogate, but easy to assess, proxy for physical activity and exercise capacity in patients with COPD who were treated with tiotropium/olodaterol FDC inhalation solution, during a 6-week routine clinical practice in Italy. Moreover, we evaluated the patient's general condition during therapy course; satisfaction with different aspects of the treatment were also determined. Remarkably, this observation period, albeit short, corresponds to the usual treatment time before assessing the efficacy of a new COPD treatment 
Table 2 Previous respiratory treatments for COPD in the safety population 6 months prior initiation of the tiotropium/ olodaterol Respimat

\begin{tabular}{lcc}
\hline Previous respiratory treatments & $n$ & $\%$ \\
\hline Number of patients & 306 & 100 \\
Previous treatment with COPD therapy & & 37.9 \\
No & 116 & 62.1 \\
Yes & 190 & 4.2 \\
Respiratory therapeutics & & 4.6 \\
Short-acting beta-2 agonist & 13 & 1.0 \\
Long-acting beta-2 agonist & 14 & 41.8 \\
Short-acting anticholinergic & 3 & 0.3 \\
Long-acting anticholinergic & 128 & 20.6 \\
Short-acting anticholinergic/short-acting $\beta$-2 agonist in fixed combination & 1 & 3.6 \\
Long-acting beta-2 agonist + inhaled corticosteroid & 63 & 0.6 \\
Inhaled corticosteroid & 11 & 0.6 \\
Systemic corticosteroid & 2 & 61.4 \\
Theophylline & 2 & 1.0 \\
Prescription of previous respiratory COPD treatment & & 0.3 \\
Continuation of an existing regimen & 188 & \\
New prescription at enrollment & 3 & \\
Discontinued at enrollment & 1 & \\
\hline
\end{tabular}

and this choice also limits the patients' dropout from the study. The number of exacerbators was unexpectedly high: however, the aim of our study was not to investigate the factors associated with exacerbations, which should be addressed in dedicated analyses.

Although with all the limitations of any observational, uncontrolled study, data showed improvements of the level of physical activity, with GOLD group D patients, presenting the more severe disease, showing the highest success rate, followed by patients assigned to group $\mathrm{B}$ and $\mathrm{C}$. Intriguingly, the distribution of the therapeutic success of patients does not mirror the distribution of patients among COPD severity groups, according to the GOLD multimodality assessment. As a matter of fact, the best successful therapeutic outcome was observed in more symptomatic patients, who were assigned to groups $\mathrm{B}$ and $\mathrm{D}$. Patients assigned to groups $\mathrm{A}$ and $\mathrm{C}$ show less symptoms and more exacerbation, and are therefore less likely to benefit from tiotropium/olodaterol FDC inhalation solution.

These findings, collected in a population of patients enrolled in clinical practice, support previous evidence, which was collected in Central and Eastern Europe [27, 30, 37]. It may have major importance for clinical practice since therapeutic success is strongly associated with compliance and adherence of the patients $[27,40,41]$. Remarkably, these results were reported in patients showing multiple concomitant diseases, mainly affecting the cardiac, metabolic/endocrine, and/or vascular systems.

Our data also showed an improvement in the general state of the patient, as assessed by the PGE and the presence of a direct correlation 
Table 3 Therapeutic success (ten-point increase in the PF-10 score between visit 1 and visit 2) stratified by GOLD multimodality assessment

\begin{tabular}{llcc}
\hline GOLD groups & Therapeutic success & $\boldsymbol{n}(\%)$ & $\mathbf{9 5 \%}$ CI \\
\hline A & Therapy successful & $11(23.4)$ & $12.3-38.0$ \\
& Therapy not successful & $36(76.6)$ & \\
B & Therapy successful & $78(60.0)$ & $51.0-68.5$ \\
& Therapy not successful & $52(40.0)$ & $23.9-57.9$ \\
C & Therapy successful & $14(40.0)$ & \\
& Therapy not successful & $21(60.0)$ & $52.4-76.5$ \\
D & Therapy successful & $43(65.1)$ & \\
& Therapy not successful & $23(34.8)$ & $46.5-58.5$ \\
Total & Therapy successful & $146(52.5)$ & $132(47.5)$ \\
& Therapy not successful &
\end{tabular}

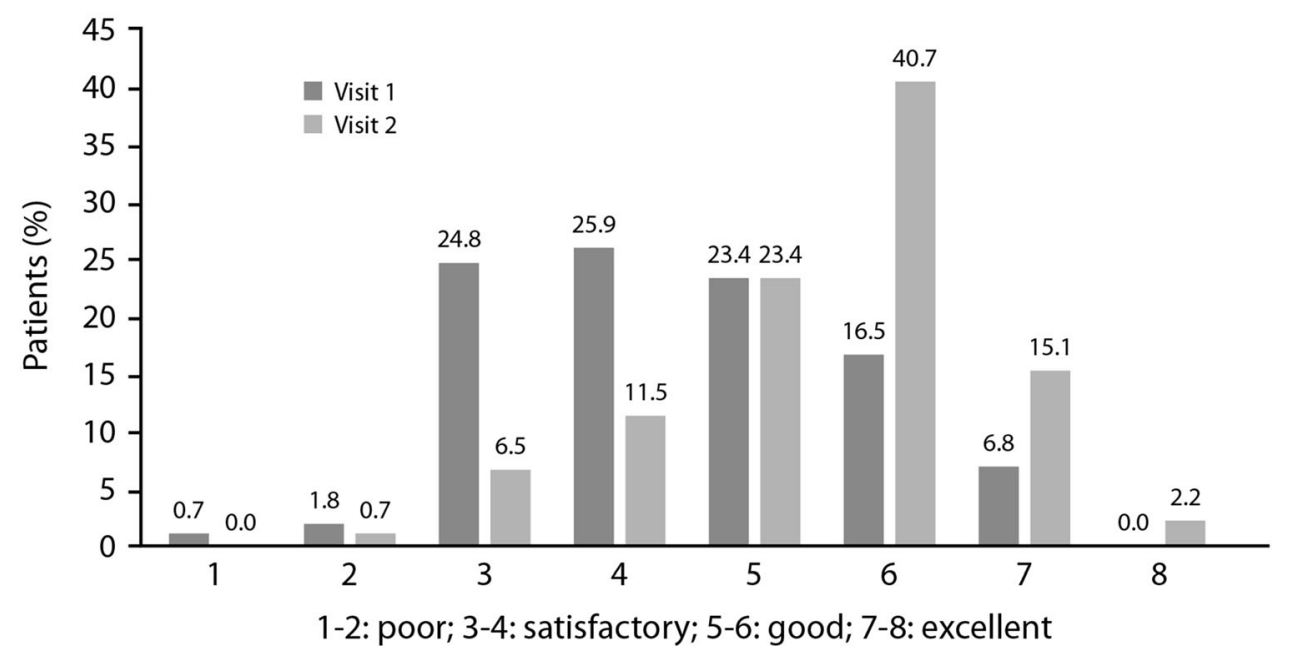

Fig. 2 Physician's global evaluation (PGE) at visit 1 and visit 2. FAS full analysis set, TS treated set

between physical functioning and general conditions. Therefore, inhaled therapy with tiotropium/olodaterol FDC with the Respimat device also seems to be associated with improvements in the well-being of the subject.

Moreover, patients reported a high satisfaction with the treatment with tiotropium/olodaterol FDC inhalation solution, inhaling from the Respimat device, and handling of the device as well, which further supports other studies in different countries and, in some cases, those that did not analyze patients with COPD exclusively [42, 43].

The overall satisfaction, combined with an improved physical functioning and general condition, may contribute to increase adherence to the prescribed medications [44], thus optimizing clinical outcomes. The once-daily dosing of the tiotropium/olodaterol FDC may also have contributed to the higher adherence compared with multiple daily doses [12]. 
Table 4 Patient satisfaction with Spiolto ${ }^{\circledR}$ Respimat ${ }^{\circledR}$

\begin{tabular}{llcc}
\hline Patient satisfaction & $\begin{array}{l}\text { Spiolto Respimat } \\
\text { treatment, } \boldsymbol{n}(\%)\end{array}$ & $\begin{array}{l}\text { Inhaling from Respimat } \\
\text { device, } \boldsymbol{n}(\%)\end{array}$ & $\begin{array}{c}\text { Handling of Respimat } \\
\text { device, } \boldsymbol{n}(\%)\end{array}$ \\
\hline Very satisfied & $31(11.1)$ & $47(16.9)$ & $57(20.5)$ \\
Satisfied & $111(39.9)$ & $119(42.8)$ & $121(43.5)$ \\
Rather satisfied & $98(35.2)$ & $83(29.9)$ & $70(25.2)$ \\
Neither satisfied nor & $29(10.4)$ & $23(8.3)$ & $19(6.8)$ \\
$\quad$ dissatisfied & & & $4(1.4)$ \\
Rather dissatisfied & $5(1.8)$ & $2(0.7)$ & $5(1.8)$ \\
Dissatisfied & $0(0)$ & $1(0.4)$ & $0(0)$ \\
Very dissatisfied & $2(0.7)$ & $1(0.4)$ & $2(0.7)$ \\
Questionnaire not & $2(0.7)$ & $2(0.7)$ & \\
$\quad$ completed & & & \\
\hline
\end{tabular}

Regarding safety, the 6-week treatment with tiotropium/olodaterol FDC showed a favorable safety profile, with a modest incidence of adverse events.

\section{Limitations}

The present study is not without its limitations, mostly those inherent to any observational study. First, it is an uncontrolled study in a field-practice population. Moreover, it is important to point out that the PF-10 was not specifically developed for evaluating limitation in respiratory patients. Although this tool is widely used in daily practice to evaluate if a person perceives any limitation in his/her physical functioning [45], it can be considered only as a proxy to evaluate changes in physical function.

\section{CONCLUSIONS}

In this field-practice study on Italian patients with COPD treated with tiotropium/olodaterol FDC with a Respimat inhaler for approximately 6 weeks under routine care conditions, the selfreported physical functioning and the general condition of patients were improved, and a high level of global satisfaction was reported regarding the treatment and use of the Respimat device. Both improvement and satisfaction were observed across all GOLD ABCD classification groups, showing the suitability of this device for different subpopulations of patients with COPD.

\section{ACKNOWLEDGEMENTS}

We acknowledge the healthcare professionals of the Otivacto study participating centers: Girolamo Pelaia (Catanzaro), Elisabetta Balestro (Padova), Marco Confalonieri (Trieste), Andrea Vianello (Padova), Alberto Ricci (Roma), Stefano Baglioni (Perugia), Antonio Spanevello (Tradate, VA), Mauro Carone (Cassano Murge, BA), Francesco Mazza (Pordenone), Roberto Torchio (Orbassano, TO), Pietro Schino (Acquaviva delle Fonti, BA), Mario Del Donno (Benevento), Guido Polese (Bussolengo, VR), Nicola Launaro (Saluzzo, CN), Guido Vagheggini (Volterra, PI), Walter Castellani (FI), Adriano Vaghi (Garbagnate Milanese, MI), Alessandro Vatrella (Fisciano, NA), Mariella D'Amato (Napoli), Giovanni Trucco (Imperia), Mauro Ferliga (Chiari-BS), Alfeo Fiore Donati (L'Aquila), Umberto Vincenzi (Foggia), Lucio Michieletto (Mestre-VE), Alfio Pennisi (Biancavilla, CT), Gerardo Palmiero (Lido di Camaiore, LU), Piero 
Candoli (Pesaro), GianGaleazzo Riario Sforza (Sesto S. Giovanni, MI), Salvatore LoCicero (Milano), George Cremona (Milano). We thank Yghea (Bioikos Ambiente s.r.l. division) and Alcedis $\mathrm{GmbH}$ for site monitoring, data collection, and analysis. We thank Erica Oltolini and Raffaella Spinello from Boehringer-Ingelheim S.p.A (Italy) for carefully managing the study. The authors also thank Dr. Domenico Scrutinio and Dr. Giorgio Castellana (Istituti Clinici Scientifici Maugeri IRCCS, Pavia, Italy) for carefully revising the paper.

Funding. The study and Rapid Service Fee were funded by Boehringer-Ingelheim S.p.A.

Medical Writing, Editorial, and Other Assistance. Medical writing assistance was provided by Dr. Luisa Granziero, PhD, Luca Giacomelli, PhD, (Polistudium SRL, Milan, Italy) and Aashni Shah (Polistudium SRL, Milan, Italy). Funding for this support was from Boehringer Ingelheim Italia.

Authorship. All named authors meet the International Committee of Medical Journal Editors (ICMJE) criteria for authorship for this article, take responsibility for the integrity of the work as a whole, and have given their approval for this version to be published.

Disclosures. Carla Scognamillo and Li Chun are employees of Boehringer Ingelheim. Mauro Carone, Alfio Pennisi, Mariella D'Amato, Alfeo Fiore Donati, Alberto Ricci, Maria Aliani, Valeria Ronsivalle, and Girolamo Pelaia have nothing to disclose.

Compliance with Ethics Guidelines. The study was approved by the local institutional Ethics Committee (Comitato Etico Regione Calabria Sezione Area Centro) and written informed consent was obtained from each participant. The study was performed in accordance with the Helsinki Declaration of 1964, and its later amendments. This study is registered with ClinicalTrials.gov (NCT03003494).

Data Availability. The datasets generated during and/or analyzed during the current study are available from the corresponding author on reasonable request.

Open Access. This article is licensed under a Creative Commons Attribution-NonCommercial 4.0 International License, which permits any non-commercial use, sharing, adaptation, distribution and reproduction in any medium or format, as long as you give appropriate credit to the original author(s) and the source, provide a link to the Creative Commons licence, and indicate if changes were made. The images or other third party material in this article are included in the article's Creative Commons licence, unless indicated otherwise in a credit line to the material. If material is not included in the article's Creative Commons licence and your intended use is not permitted by statutory regulation or exceeds the permitted use, you will need to obtain permission directly from the copyright holder. To view a copy of this licence, visit http:// creativecommons.org/licenses/by-nc/4.0/.

\section{REFERENCES}

1. Larson JL, Webster KE. Feasibility and acceptability of active for life with COPD, an intervention to increase light physical activity in people with COPD. Heart Lung. 2020. https://doi.org/10.1016/j. hrtlng.2020.01.002(Epub ahead of print).

2. Minakata Y, Motegi T, Ueki J, Gon Y, Nakamura S, Anzai T, Hirata K, Ichinose M. Effect of tiotropium/ olodaterol on sedentary and active time in patients with COPD: post hoc analysis of the VESUTO ${ }^{\circledR}$ study. Int J Chron Obstruct Pulmon Dis. 2019;14: 1789-801.

3. Garcia-Aymerich J, Lange P, Benet M, Schnohr P, Anto JM. Regular physical activity reduces hospital admission and mortality in chronic obstructive pulmonary disease: a population-based cohort study. Thorax. 2006;61(9):772-8. https://doi.org/ 10.1136/thx.2006.060145.

4. Waschki B, Kirsten A, Holz O, Muller KC, Meyer T, Watz $H$, Magnussen $H$. Physical activity is the strongest predictor of all-cause mortality in patients with COPD: a prospective cohort study. Chest. 2011;140(2):331-42. https://doi.org/10.1378/chest. $10-2521$. 
5. Ko FWS, Chan KP, Hui DSC. Comprehensive care for chronic obstructive pulmonary disease. J Thorac Dis. 2019;11(Suppl 17):S2181-S21912191. https:// doi.org/10.21037/jtd.2019.09.81.

6. GOLD Global Initiative for Chronic Obstructive Lung Disease, Global strategy for the diagnosis, management, and prevention of chronic obstructive pulmonary disease. (2019). https://goldcopd. org/wp-content/uploads/2018/11/GOLD-2019-v1. 7-FINAL-14Nov2018-WMS.pdf. Accessed April 2019.

7. Watz H, Waschki B, Meyer T, Magnussen H. Physical activity in patients with COPD. Eur Respir J. 2009;33(2):262-72.

8. Di Marco F, Santus P, Sotgiu G, Blasi F, Centanni S. Does improving exercise capacity and daily activity represent the holistic perspective of a new COPD approach? COPD. 2015;12(5):575-81.

9. Shioya T, Sato S, Iwakura M, Takahashi H, Terui Y, Uemura S, Satake M. Improvement of physical activity in chronic obstructive pulmonary disease by pulmonary rehabilitation and pharmacological treatment. Respir Investig. 2018;56(4):292-306. https://doi.org/10.1016/j.resinv.2018.05.002.

10. Troosters T, van der Molen T, Polkey M, Rabinovich RA, Vogiatzis I, Weisman I, Kulich K. Improving physical activity in COPD: towards a new paradigm. Respir Res. 2013;14(1):115.

11. Tashkin DP, Ferguson G. Combination bronchodilator therapy in the management of chronic obstructive pulmonary disease. Respir Res. 2013;14: 49. https://doi.org/10.1186/1465-9921-14-49.

12. Blair HA. Tiotropium/olodaterol: a review in COPD. Drugs. 2019;79(9):997-1008. https://doi.org/10. 1007/s40265-019-01133-w.

13. Ichinose $M$, Nishimura $M$, Akimoto $M$, Kurotori $Y$, Zhao Y, de la Hoz A, Mishima M. Tiotropium/olodaterol versus tiotropium in Japanese patients with COPD: results from the DYNAGITO study. Int J Chron Obstruct Pulmon Dis. 2018;13:2147-56. https://doi.org/10.2147/COPD.S169941.

14. LaForce C, Derom E, Bothner U, Kloer IM, Trampisch M, Buhl R. Long-term safety of tiotropium/ olodaterol Respimat ${ }^{\circledR}$ in patients with moderate-tovery severe COPD and renal impairment in the TONADO ${ }^{\circledR}$ studies. Int J Chron Obstruct Pulmon Dis. 2018;13:1819-31.

15. Maltais F, Hamilton A, Voß F, Maleki-Yazdi MR. Dose determination for a fixed-dose drug combination: a phase II randomized controlled trial for tiotropium/olodaterol versus tiotropium in patients with COPD. Adv Ther. 2019;36(4):962-8. https:// doi.org/10.1007/s12325-019-00911-y.

16. Martinez FJ, Abrahams RA, Ferguson GT, Bjermer L, Grönke L, Voß F, Singh D. Effects of baseline symptom burden on treatment response in COPD. Int J Chron Obstruct Pulmon Dis. 2019;14:181-94. https://doi.org/10.2147/COPD.S179912.

17. Maltais F, Aumann JL, Kirsten AM, Nadreau É, Macesic H, Jin X, Hamilton A, O'Donnell DE. Dual bronchodilation with tiotropium/olodaterol further reduces activity-related breathlessness versus tiotropium alone in COPD. Eur Respir J. 2019. https://doi.org/10.1183/13993003.02049-2018.

18. Ferguson GT, Buhl R, Bothner U, Hoz A, Voß F, Anzueto A, Calverley PMA. Safety of tiotropium/ olodaterol in chronic obstructive pulmonary disease: pooled analysis of three large, 52-week, randomized clinical trials. Respir Med. 2018;143: 67-73. https://doi.org/10.1016/j.rmed.2018.08.012.

19. Maltais F, O'Donnell D, Gáldiz Iturri JB, Kirsten AM, Singh D, Hamilton A, Tetzlaff K, Zhao Y, Casaburi R. Effect of 12 weeks of once-daily tiotropium/olodaterol on exercise endurance during constant work-rate cycling and endurance shuttle walking in chronic obstructive pulmonary disease. Ther Adv Respir Dis. 2018;12:1753465818755091. https:// doi.org/10.1177/1753465818755091.

20. Bai C, Ichinose M, Lee $\mathrm{SH}$, Lee $\mathrm{KH}$, Jöns $\mathrm{O}$, Bothner $\mathrm{U}$, Zhao Y, Buhl R. Lung function and long-term safety of tiotropium/olodaterol in East Asian patients with chronic obstructive pulmonary disease. Int $\mathrm{J}$ Chron Obstruct Pulmon Dis. 2017;2017(12):3329-39. https://doi.org/10.2147/ COPD.S137719.eCollection.

21. Miravitlles M, Urrutia G, Mathioudakis AG, Ancochea J. Efficacy and safety of tiotropium and olodaterol in COPD: a systematic review and metaanalysis. Respir Res. 2017;18(1):196. https://doi. org/10.1186/s12931-017-0683-X.

22. O'Donnell DE, Casaburi R, Frith P, Kirsten A, De Sousa D, Hamilton A, Xue W, Maltais F. Effects of combined tiotropium/olodaterol on inspiratory capacity and exercise endurance in COPD. Eur Respir J. 2017. https://doi.org/10.1183/13993003. 01348-2016.

23. Buhl R, Maltais F, Abrahams R, Bjermer L, Derom E, Ferguson G, Fležar M, Hébert J, McGarvey L, Pizzichini E, Reid J, Veale A, Grönke L, Hamilton A, Korducki L, Tetzlaff K, Waitere-Wijker S, Watz H, Bateman E. Tiotropium and olodaterol fixed-dose combination versus mono-components in COPD (GOLD 2-4). Eur Respir J. 2015;45(4):969-79. https://doi.org/10.1183/09031936.00136014. 
24. Ferguson GT, Karpel J, Bennett N, Clerisme-Beaty E, Grönke L, Voß F, Buhl R. Effect of tiotropium and olodaterol on symptoms and patient-reported outcomes in patients with COPD: results from four randomised, double-blind studies. NPJ Prim Care Respir Med. 2017;27(1):7. https://doi.org/10.1038/ s41533-016-0002-x.

25. Dekhuijzen R, Lavorini F, Usmani OS, van Boven JFM. Addressing the impact and unmet needs of nonadherence in asthma and chronic obstructive pulmonary disease: where do we go from here? J Allergy Clin Immunol Pract. 2018;6(3):785-93. https://doi.org/10.1016/j.jaip.2017.11.027.

26. Dhand R. Inhaled drug therapy 2016: the year in review. Respir Care. 2017;62(7):978-96. https://doi. org/10.4187/respcare.05624.

27. Valipour A, Tamm M, Kociánová J, Bayer V, Sanzharovskaya M, Medvedchikov A, Haaksma-Herczegh M, Mucsi J, Fridlender Z, Toma C, Belevskiy A, Matula B, Šorli J. Improvement in self-reported physical functioning with tiotropium/olodaterol in central and Eastern European COPD patients. Int J Chron Obstruct Pulmon Dis. 2019;14:2343-54. https://doi.org/10.2147/COPD.S204388.

28. Steinmetz KO, Abenhardt B, Pabst S, Hänsel M, Kondla A, Bayer V, Buhl R. Assessment of physical functioning and handling of tiotropium/olodaterol Respimat $\AA$ in patients with COPD in a real-world clinical setting. Int J Chron Obstruct Pulmon Dis. 2019;14:1441-533. https://doi.org/10.2147/COPD. S195852.

29. Ichinose M, Minakata Y, Motegi T, Ueki J, Gon Y, Seki T, Anzai T, Nakamura S, Hirata K. Efficacy of tiotropium/olodaterol on lung volume, exercise capacity, and physical activity. Int J Chron Obstruct Pulmon Dis. 2018;13:1407-19. https://doi.org/10. 2147/COPD.S166023.

30. Sauer R, Hänsel M, Buhl R, Rubin RA, Frey M, Glaab T. Impact of tiotropium + olodaterol on physical functioning in COPD: results of an open-label observational study. Int J Chron Obstruct Pulmon Dis. 2016;11:891-8.

31. Ishii $\mathrm{T}$, Nishimura $\mathrm{M}$, Akimoto $\mathrm{A}$, James $\mathrm{MH}$, Jones P. Understanding low COPD exacerbation rates in Japan: a review and comparison with other countries. Int J Chron Obstruct Pulmon Dis. 2018;13: 3459-71. https://doi.org/10.2147/COPD.S165187.

32. Spiolto ${ }^{\circledR}$ Respimat ${ }^{\circledR}$ SmPC. https://www.ema.europa. eu/en/documents/psusa/olodaterol/tiotropium-listnationally-authorised-medicinal-products-psusa/ 00010489/201705_en.pdf. Accessed 10 June 2020.

33. Palmiotti GA, Lacedonia D, Liotino V, Schino P, Satriano F, Di Napoli PL, Sabato E, Mastrosimone V,
Scoditti A, Carone M, Costantino E, Resta E, Attolini E, Barbaro MPF. Adherence to GOLD guidelines in real-life COPD management in the Puglia region of Italy. Int J Chron Obstruct Pulmon Dis. 2018;13: 2455-62.

34. Ramsey SD. Suboptimal medical therapy in COPD: exploring the causes and consequences. Chest. 2000;117(2 suppl):33S-7S.

35. Bestall JC, Paul EA, Garrod R, Garnham R, Jones PW, Wedzicha JA. Usefulness of the Medical Research Council (MRC) dyspnoea scale as a measure of disability in patients with chronic obstructive pulmonary disease. Thorax. 1999;54(7):581-6.

36. Ware JE Jr, Sherbourne CD. The MOS 36-item shortform health survey (SF-36). I. Conceptual framework and item selection. Med Care. 1992;30(6): 473-83.

37. Rau-Berger H, Mitfessel H, Glaab T. Tiotropium Respimat ${ }^{\circledR}$ improves physical functioning in chronic obstructive pulmonary disease. Int J Chron Obstruct Pulmon Dis. 2010;5:367-73. https://doi. org/10.2147/COPD.S14082.

38. Cohen J. Statistical power analysis for the behavioral sciences. 2nd ed. Hillsdale: Lawrence Erlbaum Associates; 1988.

39. Bettoncelli G, Blasi F, Brusasco V, Centanni S, Corrado A, De Benedetto F, De Michele F, Di Maria GU, Donner CF, Falcone F, Mereu C, Nardini S, Pasqua F, Rossi A, Sanguinetti CM, The clinical, and integrated management of COPD. An official document of AIMAR (Interdisciplinary Association for Research in Lung Disease), AIPO (Italian Association of Hospital Pulmonologists), SIMER (Italian Society of Respiratory Medicine), SIMG (Italian Society of General Medicine). Multidiscip Respir Med. 2014;9(1):25. https://doi.org/10.1186/20496958-9-25.

40. Jung E, Pickard AS, Salmon JW, Bartle B, Lee TA. Medication adherence and persistence in the last year of life in COPD patients. Respir Med. 2009;103(4):525-34. https://doi.org/10.1016/j. rmed.2008.11.004.

41. Vestbo J, Anderson JA, Calverley PM, Celli B, Ferguson GT, Jenkins C, Knobil K, Willits LR, Yates JC, Jones PW. Adherence to inhaled therapy, mortality and hospital admission in COPD. Thorax. 2009;64(11):939-43. https://doi.org/10.1136/thx. 2009.113662.

42. Valipour A, Bayer V, Kondla A, Marseille A, Medvedchikov A, Haaksma-Herczegh M, Zehendner CM. Assessment of patient experiences with Respimat ${ }^{\circledR}$ in everyday clinical practice. Am J Respir Crit Care Med. 2019;199:A3311. https://doi. 
org/10.1164/ajrccm-conference.2019.199.1_ MeetingAbstracts.A3311.

43. Hodder R, Price D. Patient preferences for inhaler devices in chronic obstructive pulmonary disease: experience with Respimat Soft Mist inhaler. Int J Chron Obstruct Pulmon Dis. 2009;4:381-90.

44. Rogliani P, Calzetta L, Braido F, Cazzola M, Clini E, Pelaia G, Rossi A, Scichilone N, Di Marco F. LABA/ LAMA fixed-dose combinations in patients with COPD: a systematic review. Int J Chron Obstruct
Pulmon Dis. 2018;4(13):3115-300. https://doi.org/ 10.2147/COPD.S170606.

45. White DK, Wilson JC, Keysor JJ. Measures of adult general functional status: SF-36 Physical Functioning Subscale (PF-10), Health Assessment Questionnaire (HAQ), Modified Health Assessment Questionnaire (MHAQ), Katz Index of Independence in Activities of Daily Living, Functional Independence Measure (FIM), and OsteoarthritisFunction-Computer Adaptive Test (OA-FunctionCAT). Arthritis Care Res (Hoboken). 2011;63(Suppl 11):S297-S307. 